\title{
Caesarean sections and breastfeeding initiation among migrants in Switzerland
}

\author{
Sonja Merten, Corinne Wyss, Ursula Ackermann-Liebrich \\ Institute of Social and Preventive Medicine, University of Basel, Switzerland
}

Submitted: 7 March 2006; Revised: 28 October 2006; Accepted: 19 February 2007

\begin{abstract}
Summary
Objectives: Twenty-six percent of all women giving birth in Switzerland are of non-Swiss nationality. Differences in reproductive health outcomes such as preterm deliveries, Caesarean sections, and breastfeeding initiation for motherchild pairs of various nationalities are investigated, and the influence of the educational level was assessed. In order to identify trans-national differences, national breastfeeding rates from 22 countries and Caesarean section rates from 24 countries were compared to the rates in Swiss hospitals.
\end{abstract}

Study Sample: Drawing on routinely collected monitoring data, 37332 mother-child pairs from various nationalities, who delivered in Swiss Baby-Friendly hospitals between 2000 and 2002 , were included in the study. All nationalities with at least 150 deliveries were coded individually, while the remaining were summarised in regional groups.

Results: Sub-Saharan African, Latin American and Asian mothers had higher rates of Caesarean sections compared to Swiss mothers $(\mathrm{OR}=1.77,95 \% \mathrm{Cl} 1.49-2.22$; OR $=1.80,1.51-$ $2.17 ; O R=1.37,1.18 .1 .59)$. African and Asian children were at an increased risk of being transferred to neonatal care units $(\mathrm{OR}=1.48,95 \% \mathrm{Cl} 1.19-1.83 ; \mathrm{OR}=1.45,1.21-1.73 ;)$. In addition, infants from Balkan countries, who showed lowest Caesarean section rates, were also more likely to be transferred to an ICU (OR $=1.30,95 \% \mathrm{Cl} 1.12-1.52)$. Apart from the country or region of origin, the maternal educational level was an important influence and modified the effect of the mother's nationality.

Mothers from all regions, apart from Western Europe, were significantly more likely to breastfeed their children after being discharged. Established determinants for breastfeeding duration, including feeding exclusively with breast milk in maternity wards, early initiation of breastfeeding, rooming-in and pacifier use, varied according to nationality.
The comparison of Caesarean section and breastfeeding rates with the rates in the mother's country of origin additionally investigates the relation between reproductive health outcomes of migrant women in Switzerland compared to their country of origin. In both cases, a significant rank correlation (Spearman) could be established between the rate in Swiss hospitals and the rate in the mother's country of origin $(P<$ $0.001, \mathrm{P}=0.04$ ).

Conclusions: Our data confirms inequalities in reproductive health outcomes and responses to health promotion programmes among migrant women in Switzerland. These differences are dependent on educational level and on the mothers' nationality. The large variation suggests that different trans-national experiences play some role in healthrelated decision-making and access to health care. This should be considered when planning health promotion programs and the individual counselling of pregnant mothers in Switzerland.

Keywords: Migration - Mother and Child Health - Breastfeeding Caesarean section - Social inequality.

In Switzerland, the proportion of deliveries by mothers of foreign nationality is as high as $26 \%$, but hitherto, only few studies have addressed reproductive health outcomes for these women (Bollini \& Wanner 2006; Bollini \& Siem 1995; Lehmann et al. 1990). Female migrants are considered to be a vulnerable group in respect to reproductive health (WHO Euro 2003). Yet, findings vary between groups and settings. In industrialised countries, migrant and ethnic minority women either displayed a greater risk of low birth weight and perinatal morbidity and mortality, and a higher risk for a Caesarean section (Ibison 2005; Braveman et al. 1995), or 
showed a similar or lower risk (Leslie et al. 2003; Page 2004; Rizzo et al. 2004; Matthias et al. 2006). Also, breastfeeding rates vary between ethnic minorities in Western European countries (Griffiths et al. 2005; Ruowei et al. 2002; Crost \& Kaminski 1998). Social inequality and immigration policies, affecting access to health care, or genetic differences of Asian, African or Latin American minorities, have been discussed as risk factors.

In Switzerland, migrants from the European Region form the largest group. They differ widely in terms of their cultural and socio-economic background, ranging from skilled professionals from high-income, to asylum seekers and unskilled workers from low-income countries. It has been shown that infant mortality is higher in the case of some non-Swiss nationalities, as is the proportion of low birth weight infants (Bollini \& Wanner 2006). Less has been reported on the influence of nationality and socio-economic characteristics on perinatal complications and mode of delivery. In Switzerland, Caesarean section (C-section) rates have been continuously rising over the past years and comprised $29 \%$ of all deliveries in 2003, suggesting an increasing number of elective $\mathrm{C}$-sections also among the migrant population. C-sections have been associated with an increased risk of maternal mortality and morbidity (Bewley \& Cockburn 2002). In addition, the costs of a $\mathrm{C}$-section are estimated to be about twice as high as for vaginal deliveries (BFS 2005). Furthermore, C-sections go hand-in-hand with a lower probability to breastfeed (Merten \& Ackermann-Liebrich 2004). With regard to the migrant population and breastfeeding, it has also been shown that the duration of full breastfeeding is shorter for non-Swiss children (Merten et al. 2005b). This despite the fact that in Switzerland, breastfeeding rates have increased over the last 10 years due in part to breastfeeding promotion campaigns such as the Baby-Friendly Hospital Initiative (BFHI) (Merten et al. 2005a). But so far no co-ordinated mother and child health programmes address migrant women, and it remains unclear to what extent migrant women and their children can profit from health promotion initiatives such as the BFHI.

As in the case of low birth weight, elective C-section, or breastfeeding initiation, reproductive health outcomes depend in part on maternal health related behaviour and decisionmaking. Qualitative studies addressing maternal behaviour showed how migrants relied on a combination of personal and collective trans-national resources: strategies common in countries of origin influenced treatment decisions and healthrelated actions in the country of immigration (Hilfinger Messias 2002; Gilgen 2005). Individual risk factors, structural aspects determining access to reproductive health care, and culturally shaped maternal decision-making have to be considered likewise as relevant factors for health outcomes.

\section{Objectives}

In this paper we compare different reproductive health outcomes between women from various origins, who gave birth in Switzerland. For this purpose, we explore routinely collected data on preterm deliveries, mode of delivery and the transfer to intensive care units (ICU) as well as on breastfeeding initiation rates and compliance with breastfeeding promotion guidelines (BFHI). More specifically we analyse differences in risk factors and practices surrounding delivery among migrant women, who gave birth in Swiss Baby-Friendly health facilities between 2000 and 2002. The effects of maternal educational levels on Caesarean sections and related factors, as well as breastfeeding initiation for migrants in Switzerland, are investigated. Caesarean section rates and breastfeeding initiation are then compared for migrant women with rates in their country of origin to explore the influence of the cultural background. As elective Caesarean sections and infant feeding practices require mothers to take decisions and participate, differences between nationalities and correlations with rates in the mother's country of origin could indicate culturally shaped maternal decision-making.

\section{Methods}

For this study we draw on a large data set of routinely collected information from Swiss Baby-Friendly health facilities, which has been described in detail before (Merten \& Ackermann-Liebrich 2004). Midwives and nurses continuously documented the mode of delivery, health status, and breastfeeding initiation for every mother-child pair using a standardised form. In addition the data-set contains detailed information on maternal socio-demographic characteristics. The quality of the data is annually evaluated since 1999. The information encompassed type of delivery, birth weight, gestational age, sex, multiple birth, length of stay in hospital, and whether the mother or the child had to be transferred to an intensive care or a neonatal care unit, which served as a proxy for perinatal complications. In relation to infant feeding, detailed information was obtained on breastfeeding pattern, the time of first suckling, rooming-in, supplementary feeding and its indications, and the use of teats and pacifiers. Additional information on mother-child pairs includes parity, maternal age, education (vocational training $<2$ years, two or more years, or higher degree), and nationality was also compiled. Although there is little standardised information on medical conditions available from the routine data, the socio-demographic information allows for a comparison of important determinants of perinatal health outcomes. 
For this analysis, we used the data sets from 2000 to 2002, comprising 79509 neonates. Data collected after this date no longer provided information on maternal education, which is why we restricted the study to the period mentioned. According to the official number of births in Switzerland, our sample represents $94.7 \%$ of all infants born during this period in the 71 hospitals covered by the study. All types of health facilities were included in the sample (university teaching hospitals, regional and district hospitals, and private clinics), and all regions were represented. At national level (including births in non Baby-Friendly health facilities), the sample encompassed approximately one-third of all births in Switzerland during the period in question.

All 29832 infants with non-Swiss mothers and a specified nationality have been included as has a random sub-sample of 7500 Swiss mother-child pairs out of 48426 , which was large enough to allow subgroup analysis but reduced the data cleaning. The sub-sample was compared with the full sample to identify potential differences; no significant differences were found. We performed the analysis with a final sample of 37332 mother-child pairs. If more than 150 deliveries occurred from mothers of the same nationality, which was the case for 30 countries, nationality was coded accordingly, while the remaining 4287 infants whose mothers were nonSwiss were subsumed in regional groups.

Breastfeeding was classified according to the following definitions: Exclusively breast-milk-fed infants received nothing apart from breast milk during their stay in the maternity ward (WHO 1991). "Ever breastfed" comprised all neonates who were breastfed on the maternity ward.

\section{Statistical analysis}

Differences between nationalities in terms of maternal and infant characteristics, type of delivery, breastfeeding rates and associated health facility factors were compared. To estimate the effect of nationality on preterm delivery, Caesarean section, transfer to intensive care unit (ICU), and breastfeeding initiation, we performed a multivariate logistic regression for every dependent variable, and included nationality, maternal education, age, and parity, and sex of the child, as covariates. Information on pregnancy course, peri-natal complications, other medical conditions or previous deliveries was unavailable. We also controlled for the health facility where delivery occurred and adjusted the standard errors for clustering in hospitals. To allow for effect modification of maternal education, interaction terms for nationality and maternal education were added to the logistic regression. Based on this model, adjusted proportions of preterm delivery, Caesarean section, transfer to intensive care unit (ICU) and breastfeeding initiation were calculated for each region and nationality, stratified according to educational level, and shown on a graph.

To establish whether the rates for "ever breastfed" infants and Caesarean sections from different nationalities, corresponded with the rates observed in the respective countries of origin, the observed rate in the country of origin, if available, was compared in a table with the rate in the Swiss hospitals. A non-parametric rank correlation test was performed. STATA 8 was used as the statistical package.

\section{Results}

Significant differences between nationalities were found for all maternal socio-demographic characteristics recorded (Tab. 1): maternal education and marital status, parity, maternal age, and whether delivery occurred in a private clinic. The proportion of mothers with a higher diploma or a university degree varied from $2 \%$ (Kosovo, Macedonia, Portugal) to $67 \%$ (USA). Apart from US American mothers, over $50 \%$ of women of British, French and Russian nationality belonged to the highest educational level, followed by German, Dutch and Polish mothers. The proportion of deliveries in private hospitals was also highest among these nationalities. For most Western European and US American mothers, the average age at birth was high (average $>30$ years), while mothers from countries of the former Yugoslav Republic were younger, with an average age ranging between 26 and 29 years.

Apart from Peruvian and Brazilian mothers, less than $10 \%$ of the women from developing countries had been in higher education, and they were less likely to give birth in a private clinic. With the exception of Somali women, for whom a mean parity of 3 was calculated, they did not have substantially more children than mothers from industrialised countries.

Sub-Saharan African and Asian mothers had higher proportions of preterm deliveries and higher rates of multiple births (Tab. 2). Transfers to NICU were also elevated for Sub-Saharan African and Asian mothers, the mean birth weight being lowest for newborn with mothers from these regions.

Also results for Caesarean sections varied greatly between nationalities. Brazilian mothers had the highest proportion (42\%), followed by Congolese and other Latin American nationals. While the high proportion of Caesarean sections among Congolese women could be explained in part by the high rate of preterm deliveries, this was not the case for the Brazilian and other Latin American mothers. Mothers from Morocco and some Asian countries also displayed proportions of Caesarean sections, above $30 \%$. This corresponded in part to the elevated proportions of preterm deliveries.

From the industrialised countries, only the Caesarean sec- 
Table 1 Maternal characteristics and place of delivery by citizenship

\begin{tabular}{|c|c|c|c|c|c|c|c|c|c|}
\hline & \multirow{2}{*}{$\begin{array}{c}\text { Deliveries } 2000- \\
2002 \\
(n=37332) \\
n\end{array}$} & \multicolumn{2}{|c|}{$\begin{array}{l}\text { Higher diploma/ } \\
\text { university degree } \\
\quad(n=20353)\end{array}$} & \multicolumn{2}{|c|}{$\begin{array}{l}\text { Mean } \\
\text { maternal } \\
\text { age }\end{array}$} & \multicolumn{2}{|c|}{$\begin{array}{l}\text { Mean } \\
\text { parity }\end{array}$} & \multicolumn{2}{|c|}{$\begin{array}{l}\text { Deliveries in private } \\
\text { hospitals }\end{array}$} \\
\hline & & $\mathrm{n}$ & $(\%)$ & years & (SE) & parity & (SE) & $\mathrm{n}$ & $(\%)$ \\
\hline Switzerland & 7704 & 996 & (20) & 31.0 & $(0.05)$ & 1.8 & $(0.01)$ & 2196 & (29) \\
\hline African countries & 1167 & 125 & $(11)$ & 29.8 & $(0.12)$ & 2.1 & $(0.03)$ & 135 & (7) \\
\hline Angola & 161 & 4 & (5) & 28.8 & $(0.39)$ & 2.5 & $(0.10)$ & 0 & (0) \\
\hline Dem. Rep. Congo & 237 & 5 & (4) & 29.7 & $(0.36)$ & 2.3 & $(0.09)$ & 4 & (2) \\
\hline Morocco & 375 & 21 & (10) & 31.3 & $(0.27)$ & 1.6 & $(0.04)$ & 30 & (8) \\
\hline Somalia & 230 & 5 & (4) & 28.7 & $(0.41)$ & 3.1 & $(0.14)$ & 6 & (3) \\
\hline Tunisia & 164 & 9 & (10) & 29.6 & $(0.41)$ & 1.9 & $(0.09)$ & 6 & (4) \\
\hline Latin American countries & 911 & 190 & (22) & 30.6 & $(0.14)$ & 1.7 & $(0.02)$ & 256 & (16) \\
\hline Brazil & 548 & 40 & (16) & 30.0 & $(0.23)$ & 1.6 & $(0.03)$ & 81 & (15) \\
\hline Dominican Republic & 206 & 5 & (4) & 29.1 & $(0.38)$ & 2.0 & $(0.07)$ & 16 & (8) \\
\hline Peru & 157 & 26 & (29) & 31.8 & $(0.49)$ & 1.6 & $(0.06)$ & 27 & (17) \\
\hline Asian countries & 2306 & 216 & $(12)$ & 29.8 & $(0.09)$ & 1.8 & $(0.02)$ & 379 & (11) \\
\hline Philippines & 223 & 12 & (10) & 31.1 & $(0.37)$ & 1.8 & $(0.07)$ & 33 & (15) \\
\hline Sri Lanka & 1563 & 30 & (4) & 29.4 & $(0.12)$ & 1.8 & $(0.02)$ & 85 & (5) \\
\hline Thailand & 307 & 9 & (5) & 29.9 & $(0.30)$ & 1.8 & $(0.05)$ & 29 & (10) \\
\hline Viet Nam & 213 & 12 & (11) & 30.0 & $(0.34)$ & 1.8 & $(0.06)$ & 20 & (10) \\
\hline Balkan and Turkey & 10227 & 202 & (4) & 26.9 & $(0.05)$ & 2.0 & $(0.01)$ & 832 & (8) \\
\hline Albania & 900 & 21 & (5) & 26.4 & $(0.16)$ & 2.1 & $(0.04)$ & 40 & (4) \\
\hline Bosnia, Herzegovina & 853 & 20 & (4) & 27.6 & $(0.19)$ & 1.8 & $(0.03)$ & 58 & (7) \\
\hline Croatia & 682 & 22 & (6) & 28.8 & $(0.21)$ & 1.8 & $(0.03)$ & 124 & (18) \\
\hline Kosovo & 2168 & 20 & (2) & 26.7 & $(0.11)$ & 2.2 & $(0.03)$ & 73 & (3) \\
\hline Macedonia & 1070 & 10 & (2) & 25.5 & $(0.15)$ & 1.8 & $(0.03)$ & 45 & (4) \\
\hline Serbia, Montenegro\# & 2951 & 59 & (4) & 26.7 & $(0.10)$ & 1.9 & $(0.02)$ & 311 & (11) \\
\hline Turkey & 1603 & 40 & (5) & 27.4 & $(0.13)$ & 1.8 & $(0.02)$ & 161 & (10) \\
\hline Other European countries and USA & 17377 & 1501 & (24) & 30.9 & $(0.05)$ & 1.6 & $(0.01)$ & 2070 & (19) \\
\hline Austria & 278 & 38 & (23) & 31.6 & $(0.26)$ & 1.7 & $(0.04)$ & 52 & (19) \\
\hline France & 887 & 262 & (51) & 31.9 & $(0.15)$ & 1.7 & $(0.03)$ & 241 & (28) \\
\hline Germany & 1417 & 336 & (43) & 33.0 & $(0.11)$ & 1.6 & $(0.02)$ & 278 & (20) \\
\hline Italy & 2462 & 131 & (10) & 30.2 & $(0.09)$ & 1.7 & $(0.02)$ & 457 & (19) \\
\hline Netherlands & 251 & 54 & (36) & 33.4 & $(0.23)$ & 1.8 & $(0.06)$ & 74 & (31) \\
\hline Poland & 151 & 20 & (31) & 28.9 & $(0.39)$ & 1.5 & $(0.06)$ & 30 & (20) \\
\hline Portugal & 2609 & 28 & (2) & 29.6 & $(0.10)$ & 1.7 & $(0.01)$ & 180 & (7) \\
\hline Russian Federation & 230 & 67 & (52) & 29.8 & $(0.31)$ & 1.5 & $(0.05)$ & 51 & (23) \\
\hline Spain & 900 & 76 & (14) & 31.0 & $(0.17)$ & 1.6 & $(0.03)$ & 192 & (22) \\
\hline United Kingdom & 327 & 105 & (54) & 33.3 & $(0.24)$ & 1.7 & $(0.05)$ & 158 & (51) \\
\hline USA & 161 & 63 & (67) & 33.8 & $(0.35)$ & 1.6 & $(0.06)$ & 69 & (44) \\
\hline
\end{tabular}

\# without Kosovo

tion rates of Dutch, US American and British mothers were higher than $30 \%$. Dutch mothers also had one of the highest proportions of preterm deliveries. The lowest proportions for $\mathrm{C}$-sections were found for Polish mothers and women from the former Yugoslav Republic (min. 17\%). The proportion among Swiss women was $26 \%$.

Large differences between nationalities were also apparent in breastfeeding rates (Tab. 3). The rate of never breast-fed infants ranged from $2 \%$ to $17 \%$ in the case of French mothers.
Congolese, Spanish, Dutch and Philippine mothers initiated breastfeeding for less than $90 \%$ of infants. If the compliance with the recommendations related to breastfeeding is looked at (timely first suckling, exclusive breastfeeding, roomingin, and no pacifier use) some tendencies can be observed. Mothers from Asian countries were less likely to exclusively breastfeed than African or Latin American mothers. This is not corresponding to higher proportions of Caesarean sections or perinatal complications; only timely first suckling 
Table 2 Birth weight, preterm deliveries, multiple births, Caesarean sections and transfer to intensive care unit

\begin{tabular}{|c|c|c|c|c|c|c|c|c|c|c|}
\hline & \multicolumn{2}{|c|}{ Birth weight } & \multicolumn{2}{|c|}{ Preterm deliveries } & \multicolumn{2}{|c|}{ Multiple births } & \multicolumn{2}{|c|}{ Caesarean section } & \multicolumn{2}{|c|}{$\begin{array}{l}\text { Transfer to } \\
\text { intensive care unit }\end{array}$} \\
\hline & Mean & (SE) & $\mathrm{n}$ & $(\%)$ & $\mathrm{n}$ & $(\%)$ & $\mathrm{n}$ & $(\%)$ & $\mathrm{n}$ & $(\%)$ \\
\hline Switzerland & 3278 & (6) & 679 & (9) & 271 & (4) & 2002 & (26) & 611 & (8) \\
\hline African countries & 3236 & (14) & 234 & (11) & 97 & (5) & 657 & (32) & 261 & (13) \\
\hline Angola & 3183 & (50) & 19 & (12) & 11 & (7) & 44 & (27) & 25 & (16) \\
\hline Dem. Rep. Congo & 3074 & (49) & 45 & (19) & 16 & (7) & 89 & (38) & 45 & (19) \\
\hline Morocco & 3289 & (31) & 45 & (12) & 21 & (6) & 129 & (34) & 47 & (13) \\
\hline Somalia & 3261 & (42) & 21 & (9) & 3 & (1) & 63 & (28) & 28 & (12) \\
\hline Tunisia & 3376 & (42) & 14 & (9) & 4 & (2) & 42 & (26) & 11 & (7) \\
\hline Latin American countries & 3276 & (15) & 137 & (8) & 64 & (4) & 604 & (38) & 136 & (9) \\
\hline Brazil & 3241 & (24) & 49 & (9) & 23 & (4) & 228 & (42) & 50 & (9) \\
\hline Dominican Republic & 3239 & (41) & 23 & (11) & 14 & (7) & 78 & (38) & 17 & (8) \\
\hline Peru & 3352 & (48) & 7 & (4) & 4 & (3) & 57 & (37) & 7 & (5) \\
\hline Asian countries & 3220 & (9) & 321 & (9) & 107 & (3) & 1039 & (29) & 364 & (11) \\
\hline Philippines & 3274 & (42) & 28 & (13) & 14 & (6) & 76 & (34) & 26 & (12) \\
\hline Sri Lanka & 3167 & (14) & 151 & (10) & 49 & (3) & 488 & (31) & 195 & (13) \\
\hline Thailand & 3278 & (31) & 34 & (11) & 3 & (1) & 107 & (35) & 33 & (11) \\
\hline Viet Nam & 3159 & (29) & 18 & (8) & 4 & (2) & 49 & (23) & 15 & (7) \\
\hline Balkan and Turkey & 3386 & (6) & 792 & (8) & 308 & (3) & 1973 & (19) & 865 & (9) \\
\hline Albania & 3328 & (21) & 90 & (10) & 32 & (4) & 168 & (19) & 97 & (11) \\
\hline Bosnia, Herzegovina & 3500 & (20) & 55 & (6) & 22 & (3) & 163 & (19) & 68 & (8) \\
\hline Croatia & 3458 & (21) & 43 & (6) & 36 & (5) & 139 & (20) & 50 & (7) \\
\hline Kosovo & 3402 & (12) & 130 & (6) & 50 & (2) & 297 & (14) & 146 & (7) \\
\hline Macedonia & 3355 & (17) & 85 & (8) & 18 & (2) & 184 & (17) & 80 & (8) \\
\hline Serbia, Montenegro \# & 3382 & (12) & 255 & (9) & 106 & (4) & 602 & (20) & 280 & (10) \\
\hline Turkey & 3341 & (14) & 120 & (7) & 36 & (2) & 389 & (24) & 133 & (8) \\
\hline Other European countries and USA & 3267 & (6) & 957 & (9) & 446 & (4) & 3141 & (29) & 915 & (9) \\
\hline Austria & 3265 & (34) & 20 & (7) & 11 & (4) & 78 & (28) & 18 & (7) \\
\hline France & 3234 & (19) & 73 & (8) & 29 & (3) & 253 & (29) & 77 & (9) \\
\hline Germany & 3299 & (17) & 141 & (10) & 81 & (6) & 402 & (28) & 111 & (8) \\
\hline Italy & 3247 & (11) & 192 & (8) & 100 & (4) & 705 & (29) & 176 & (7) \\
\hline Netherlands & 3296 & (41) & 37 & (15) & 15 & (6) & 84 & (33) & 25 & (10) \\
\hline Poland & 3376 & (44) & 7 & (5) & 2 & (1) & 23 & (15) & 8 & (5) \\
\hline Portugal & 3235 & (11) & 220 & (8) & 91 & (4) & 768 & (29) & 269 & (10) \\
\hline Russian Federation & 3415 & (37) & 13 & (6) & 1 & $(<1)$ & 52 & (23) & 15 & (7) \\
\hline Spain & 3211 & (18) & 77 & (9) & 35 & (4) & 257 & (29) & 79 & (9) \\
\hline United Kingdom & 3334 & (32) & 26 & (8) & 10 & (3) & 103 & (32) & 19 & (6) \\
\hline USA & 3379 & (41) & 18 & (11) & 7 & (4) & 50 & (31) & 9 & (6) \\
\hline
\end{tabular}

\#without Kosovo

inversely reflects the Caesarean section rates. Rooming-in was least common among mothers from Western European countries, who were in turn most likely to choose exclusive breastfeeding. The use of pacifiers did not consistently relate to the breastfeeding outcomes; proportions varied between $5 \%$ (France, UK) and 23\% (Somalia, Dominican Republic). Practices related to breastfeeding thus varied considerably between mothers from different countries of origin.

Of the deliveries in our sample, $17 \%$ occurred in private hospitals. In these health facilities, the Caesarean section rate was $7 \%$ higher on average than in government hospitals and reached $33 \%$. Among the private clinics in our sample, Caesarean section contributed to between $28 \%$ and $42 \%$ of the deliveries. The proportion of migrants was also higher in private hospitals ( $34 \%$ compared to $30 \%, \mathrm{p}<0.000$ ). The difference was due to a higher than average proportion of Western European and Northern American mothers giving birth in private clinics. Apart from the higher Caesarean section rate, the prevalence of never breast-fed infants was higher in private hospitals as well, although only by $2 \%(\mathrm{p}<0.000)$. 
Table 3 Breastfeeding at discharge, and adherence to recommendations of the Baby-Friendly Hospital Initiative in maternity wards

\begin{tabular}{|c|c|c|c|c|c|c|c|c|c|c|}
\hline & \multicolumn{2}{|c|}{$\begin{array}{l}\text { Breastfed at } \\
\text { discharge }\end{array}$} & \multicolumn{2}{|c|}{$\begin{array}{l}\text { Exclusively } \\
\text { breastmilk on } \\
\text { maternity ward }\end{array}$} & \multicolumn{2}{|c|}{ Timely first suckling } & \multicolumn{2}{|c|}{ Rooming-in } & \multicolumn{2}{|c|}{ Pacifier } \\
\hline & $\mathrm{n}$ & (\%) & $\mathrm{n}$ & $(\%)$ & $\mathbf{n}$ & (\%) & $\mathbf{n}$ & $(\%)$ & $\mathbf{n}$ & $(\%)$ \\
\hline Switzerland & 6669 & (92) & 2609 & (36) & 5237 & (69) & 3117 & (40) & 1046 & (15) \\
\hline African countries & 1789 & (94) & 590 & (31) & 1075 & (54) & 1089 & (53) & 226 & (11) \\
\hline Angola & 144 & (97) & 60 & (41) & 90 & (57) & 97 & (60) & 19 & (12) \\
\hline Dem. Rep. Congo & 184 & (86) & 58 & (27) & 100 & (45) & 120 & (51) & 21 & (9) \\
\hline Morocco & 329 & (95) & 97 & (28) & 181 & (49) & 164 & (44) & 28 & (8) \\
\hline Somalia & 217 & (98) & 69 & (31) & 127 & (56) & 142 & (62) & 51 & (23) \\
\hline Tunisia & 156 & (98) & 56 & (35) & 106 & (65) & 99 & (60) & 13 & (8) \\
\hline Latin American countries & 1463 & (96) & 474 & (31) & 945 & (59) & 855 & (53) & 229 & (15) \\
\hline Brazil & 488 & (94) & 155 & (30) & 301 & (56) & 267 & (49) & 98 & (19) \\
\hline Dominican Republic & 194 & (96) & 63 & (31) & 122 & (60) & 136 & (66) & 46 & (23) \\
\hline Peru & 149 & (98) & 49 & (32) & 90 & (57) & 84 & (54) & 12 & (9) \\
\hline Asian countries & 3212 & (96) & 770 & (23) & 1998 & (57) & 2045 & (58) & 547 & (16) \\
\hline Philippines & 184 & (89) & 46 & (22) & 127 & (58) & 114 & (51) & 38 & (18) \\
\hline Sri Lanka & 1465 & (98) & 279 & (19) & 817 & (53) & 952 & (61) & 267 & (17) \\
\hline Thailand & 269 & (90) & 76 & (25) & 167 & (57) & 188 & (61) & 48 & (16) \\
\hline Viet Nam & 187 & $(92)$ & 55 & (27) & 139 & (67) & 112 & (53) & 33 & (16) \\
\hline Balkan and Turkey & 9505 & (97) & 3079 & (31) & 7020 & (68) & 6150 & (59) & 1693 & (17) \\
\hline Albania & 828 & (97) & 261 & (31) & 586 & (66) & 569 & (63) & 142 & (16) \\
\hline Bosnia, Herzegovina & 778 & (96) & 245 & (30) & 591 & (70) & 469 & (55) & 143 & (18) \\
\hline Croatia & 624 & (95) & 178 & (27) & 474 & (71) & 384 & (56) & 126 & (19) \\
\hline Kosovo & 1950 & (97) & 685 & (34) & 1501 & (70) & 1272 & (59) & 326 & (16) \\
\hline Macedonia & 1001 & (98) & 335 & (33) & 732 & (69) & 690 & (64) & 178 & (18) \\
\hline Serbia, Montenegro\# & 2700 & (97) & 860 & (31) & 1988 & (68) & 1730 & (59) & 485 & (17) \\
\hline Turkey & 1517 & (98) & 482 & (31) & 1069 & (67) & 977 & (61) & 278 & (18) \\
\hline Other European countries and USA & 9381 & (93) & 3546 & (35) & 6809 & (63) & 5352 & (49) & 1328 & (13) \\
\hline Austria & 250 & (94) & 86 & (32) & 197 & (71) & 125 & (45) & 41 & (16) \\
\hline France & 652 & (83) & 273 & (35) & 487 & (58) & 322 & (36) & 39 & (5) \\
\hline Germany & 1288 & (96) & 531 & (40) & 976 & (69) & 771 & (54) & 158 & (12) \\
\hline Italy & 2145 & (93) & 728 & (32) & 1553 & (64) & 1168 & (47) & 378 & (16) \\
\hline Netherlands & 204 & (89) & 96 & (42) & 151 & (62) & 119 & (47) & 22 & (9) \\
\hline Poland & 136 & (93) & 53 & (36) & 113 & (78) & 84 & (56) & 16 & (11) \\
\hline Portugal & 2256 & (94) & 833 & (35) & 1504 & (59) & 1298 & (50) & 349 & (14) \\
\hline Russian Federation & 209 & (96) & 79 & (36) & 153 & (67) & 128 & (56) & 36 & (16) \\
\hline Spain & 727 & (87) & 264 & (32) & 521 & (60) & 457 & (51) & 125 & (15) \\
\hline United Kingdom & 248 & (93) & 128 & (48) & 209 & (66) & 143 & (44) & 16 & (5) \\
\hline USA & 132 & (92) & 54 & (38) & 107 & (68) & 89 & (55) & 11 & (7) \\
\hline
\end{tabular}

\#without Kosovo

In a next step, the associations of nationality with preterm deliveries, Caesarean sections, transfers to ICU and breastfeeding rates were adjusted for maternal and infant characteristics (Tab. 4). Despite the adjustment, considerable differences between nationalities were found for all four outcome variables.

Then, the influence of maternal education, a proxy for the social stratum, was investigated. For this purpose, crude and adjusted proportions for regional groups were plotted as graphs (Fig.
1). The maternal educational level strongly influenced the proportions of preterm deliveries showing lower rates for mothers with a higher education. The proportions however also vary greatly according to the region. Caesarean section rates equally differed, but the adjusted results showed higher rates for mothers with a better education in the case of African women and mothers from the Balkan region; this pattern was similar for the transfers of the neonate to the intensive care unit.

Among most regions, the proportions of breast-fed infants 


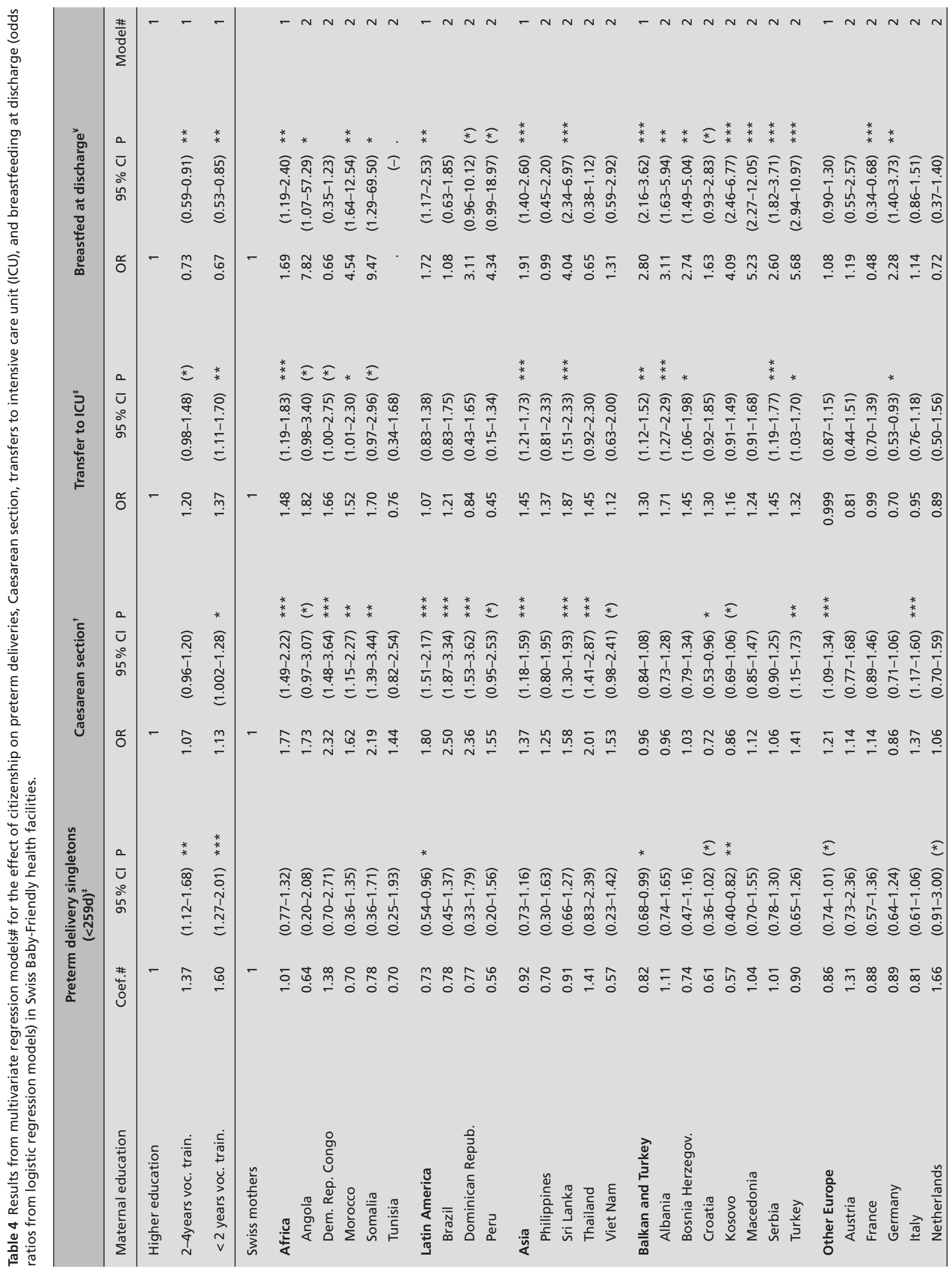




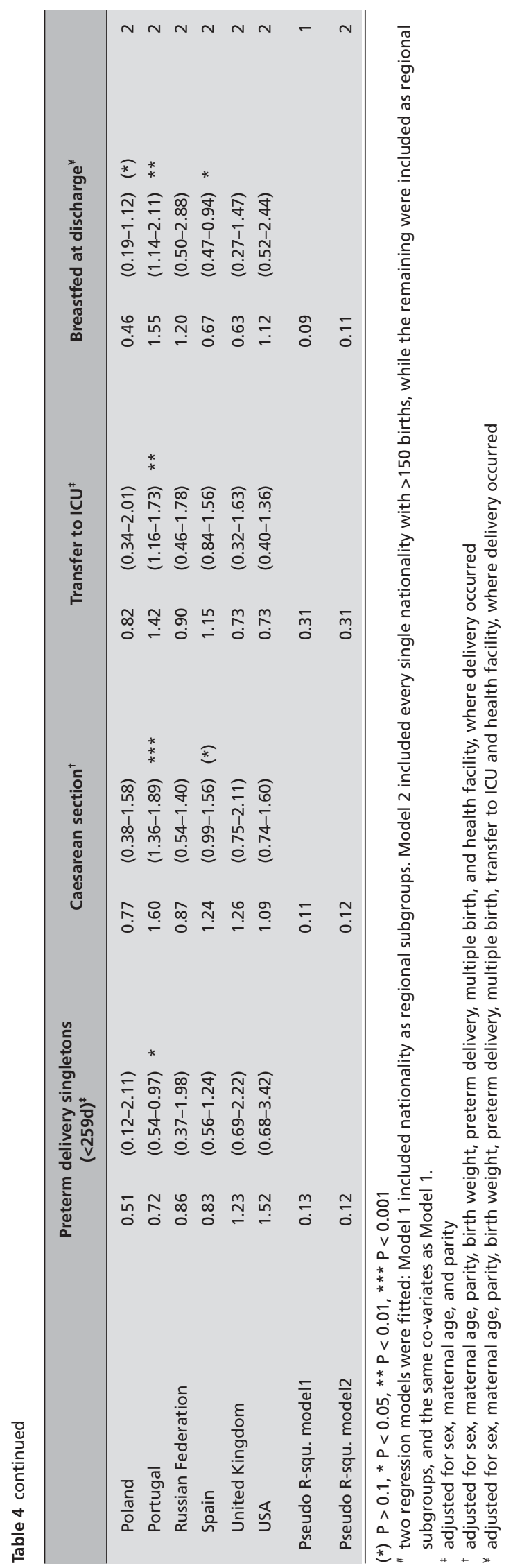

were lower in the lowest educational group compared to higher levels of education levels. For mothers from the Balkan region, the opposite was the case.

We then proceeded to investigate whether the major differences in breastfeeding and Caesarean section rates corresponded with the rates in the mother's country of origin. National breastfeeding rates were available from 22 countries, and Caesarean section rates from 24 countries. In both cases, a significant rank correlation could be established between the rate in Swiss hospitals and the rate in the mother's country of origin (Tab. 5-6). For mothers from developing countries, the correspondence with national rates in the country of origin appears lower than for mothers of European origin: Rates for Caesarean sections in Switzerland were considerably higher than the reported occurrence in their home country. Urban-rural differences in the country of origin, with a high proportion of births, which take place outside a health facility, might go some way towards explaining this discrepancy.

\section{Discussion}

Our data confirms findings that social differences and transnational experiences play a significant role for reproductive health outcomes of migrants in Switzerland. The results show great variation between different groups of migrants. While some migrant women have clearly an elevated risk for birth complications, others, like the women from the Balkan countries, have partly more favourable birth outcomes than Swiss mothers. This is in accordance with findings from recent studies, which discuss the supportive role of the migrants' family networks as resources for their greater resilience (Page 2004; Leslie et al. 2003). Apart from the country or region of origin, the maternal educational level was also an important influence.

The correlations between citizenship and country of origin with respect to Caesarean section and breastfeeding initiation, implies that for women, trans-national migration means following at least to some extent, rules and expectations which are common in their country of origin. This is supported by the observed differences in compliance with breastfeeding promotion recommendations, which cannot fully be explained by communication barriers. In the US it has been shown that the Baby-Friendly Hospital Initiative has been able to raise breastfeeding prevalence in every ethnic group, even for lower educational levels (Philipp et al. 2001). The situation may be different in Switzerland due to the cultural and linguistic diversity of the country and its immigrants.

The extent to which migrants have converged with their host country may depend on the time since immigration and on 


\begin{tabular}{lcccc}
\hline Citizenship & $\begin{array}{c}\text { Caesarean section rate } \\
\text { CH (per 1000) }\end{array}$ & $\begin{array}{c}\text { Caesarean section rate } \\
\text { coutry of origin (per } \\
\text { 1000) }\end{array}$ & Year & Ref. \\
\hline Brazil & $\mathbf{4 1 . 7}$ & 36.4 & 1996 & 1 \\
Italy & 28.7 & 31.9 & 1999 & 2 \\
Dominican Republic & 37.9 & 31.3 & 2002 & 3 \\
Portugal & 29.5 & 27.5 & 1998 & 2 \\
USA & 31.1 & 23.0 & 2000 & 4 \\
Thailand & 34.9 & 22.4 & 1996 & 5 \\
United Kingdom & 31.5 & 21.0 & 2000 & 6 \\
Germany & 28.4 & 20.9 & 2000 & 2 \\
Spain & 28.6 & 19.8 & 1997 & 2 \\
Austria & 28.1 & 18.9 & 2001 & 2 \\
France & 28.6 & 16.1 & 1999 & 2 \\
Poland & 15.3 & 16.1 & 1997 & 2 \\
Russian Federation & 22.6 & 14.7 & 2001 & 2 \\
Netherlands & 33.5 & 13.6 & 2001 & 2 \\
Turkey & 24.3 & 13.6 & 1998 & 2 \\
Albania & 18.7 & 13.0 & 2001 & 2 \\
Peru & 36.5 & 12.7 & 2000 & 7 \\
Croatia & 20.4 & 11.9 & 2001 & 2 \\
Macedonia & 17.2 & 10.2 & 2001 & 2 \\
Viet Nam & 23.0 & 10.0 & 2002 & 4 \\
Tunisia & 25.8 & 8.0 & 2000 & 4 \\
Philippines & 34.1 & 7.3 & 2003 & 8 \\
Morocco & 34.4 & 5.4 & 2003 & 9 \\
Serbia and Montenegro & 17.6 & 5.3 & 1998 & 2 \\
\hline Spearman ran & & & \\
\hline
\end{tabular}

Table 5 Caesarean section rate in Switzerland compared to Caesarean section rate in the country of origin

Spearman rank correlation coefficient $=0.41, \mathrm{P}=0.04$

1 Gomes UA, Silva AA, Bettiol $\mathrm{H}$ et al. Risk factors for the increasing caesarean section rate in Southeast Brazil: a comparison of two birth cohorts, 1978-1979 and 1994. International Journal of Epidemiology 1999; 28:687-94

2 WHO: Atlas of Health in Europe. p. 133

3 DHS Dominican Republic 2002

4 WHO: World Health Report 2005. Annex 5

5 WHO SEARO (check ref)

6 Dobson R. (Check ref)

7 DHS Peru 2000

8 DHS Philippines 2003

9 DHS Marocco 2003

integration policies. Socio-economic factors and the legal status of migrants in the host country, which may differ between nationalities, contribute to the cultural identity (Horton 2004; Hall 2004). Portes and Rumbaut summarise factors shaping migrants' identities as follows: (1) human capital, influenced by educational background, occupational skills, financial resources, and facility with the language; (2) the host society's reception of immigrant populations, particularly in relation to governmental policies, popular attitudes, and the presence of co-ethnic populations; and (3) the composition of immigrant families (Portes \& Rumbaut 2001). Following these points, barriers to pregnancy controls may partly explain the higher rates of perinatal complications particularly for women with a lower educational background. Limited information and communication skills contribute to lower use of antenatal care (Bollini \& Wanner 2006; Matthias et al. 2006; Aveyard et al.
2002; Essen et al. 2002). Another reason for a lower demand for antenatal health care and elective perinatal interventions may then be a restricted access to health care, as is the case with asylum-seekers or illegal immigrants.

Migrants from Balkan countries are more likely to be embedded in larger families and co-ethnic groups. Women may thus be less likely to pursue individual goals, which diverge from practices prevalent in their country of origin. This could explain the similar rates in the country of origin and in Switzerland for Caesarean sections as well as breastfeeding initiation. Adding to this, the family network may prove protective during pregnancy (Leslie et al. 2003; Page 2004), possibly resulting in a higher birth weight. A protective effect of the social network decreases with the time and generations since migration (McGlade et al. 2004). Generally, migrants from Balkan countries have more recently arrived in Switzerland, than for 


\begin{tabular}{lcccc}
\hline Citizenship & $\begin{array}{c}\text { Ever breastfed rate } \\
\text { CH (\%) }\end{array}$ & $\begin{array}{c}\text { Ever breastfed rate } \\
\text { country of origin (\%) }\end{array}$ & $\begin{array}{c}\text { Year of } \\
\text { survey }\end{array}$ & Ref. \\
\hline France & 83 & 53 & 2000 & 10 \\
United Kingdom & 93 & 69 & 2000 & 10 \\
USA & 92 & 70 & 2000 & 11 \\
Spain & 87 & 71 & 2001 & 10 \\
Netherlands & 89 & 75 & 2003 & 12 \\
Philippines & 89 & 87 & 2003 & 13 \\
Italy & 93 & 89 & 2000 & 10 \\
Portugal & 94 & 90 & 1999 & 10 \\
Serbia and Montenegro & 97 & 91 & 2000 & 14 \\
Dominican Republic & 96 & 96 & 2001 & 15 \\
Albania & 97 & 94 & 1998 & 16 \\
Morocco & 95 & 95 & 2003 & 17 \\
Russian Federation & 96 & 95 & 1997 & 18 \\
Austria & 94 & 96 & 1998 & 10 \\
Bosnia and Herzegovina & 96 & 96 & 1999 & 19 \\
Brazil & 94 & 96 & 1996 & 20 \\
Germany & 96 & 96 & 1998 & 10 \\
Turkey & 96 & 96 & 1998 & 21 \\
Sri Lanka & 98 & 2000 & 25 \\
Peru & 98 & 98 & 1987 & 22 \\
Tunisia & 98 & 2000 & 23 \\
Viet Nam & 98 & 24 \\
\hline Spearman ran & 98 & & 2000 \\
\hline
\end{tabular}

Table 6 Ever breastfed rate in Switzerland compared to ever breastfed rate in the country of origin

Spearman rank correlation coefficient $=0.64, \mathrm{P}<0.001$

10 Cattaneo A, Yngve A, Koletzko B et al. (2005). Protection and support of breast-feeding in Europe: current situation. Public Health Nutrition 8(1): 39-46

11 Mothers' Survey, Ross Products Div Abbot Labs, 2003

12 lalecheleague.org/cbi/bfstats03.html

13 DHS Philippines 2003

14 MICS Yugoslavia 2000, final report (p. 33)

15 MICS Dominican Republic 2001

16 [div. Authors] Report on monitoring of the feeding practices of infants and young children in Albania. Albanian Group for Protection of Breastfeeding, Ministry of Health, UNICEF. 1999. www. unicef.org/albania/Bfsurveyengl.pdf

17 DHS Morocco 2003

18 Fleischer et al. Feeding and nutrition of infants and young childrenp. WHO Regional Publications, European Series, No.87. 2000: 28

19 Breastfeeding in the Federation of Bosnia and Herzegovina. Final report 1999

20 DHS Brazil 1996

21 DHS Turkey 1998

22 DHS Sri Lanka 1987

23 DHS Peru 2000

24 MICS Tunisia 2000

25 MICS Viet Nam 2000

example Italian or Portugese women; however, individual information is not available in our data. It is possible that the co-migrated family networks of Balkan women, in contrast to those of the second- or third-generation Southern European women, would be protective during pregnancy. However, the finding that transfers to an ICU are more probable for Balkan countries partly contradicts this assumption.

Among Sub-Saharan African migrants, and some Latin American and Asian women, reproductive health risks were elevated. An explanation for a high proportion of preterm deliveries could be occupational risks like stress due to legal insecurity and precarious living conditions. Also potential shortfalls in prenatal care for women with an illegal status could lead to increased pregnancy and ultimately perinatal complications. For some nationalities, such as the Brazilian or Congolese women, the $\mathrm{C}$-section rates were strikingly high. A suspected high rate of HIV infection in certain immigrant groups e.g. Sub-Saharan African women could not explain this finding. The data set indirectly coded HIV positive mothers who would not initiate breastfeeding. On average, no more than 

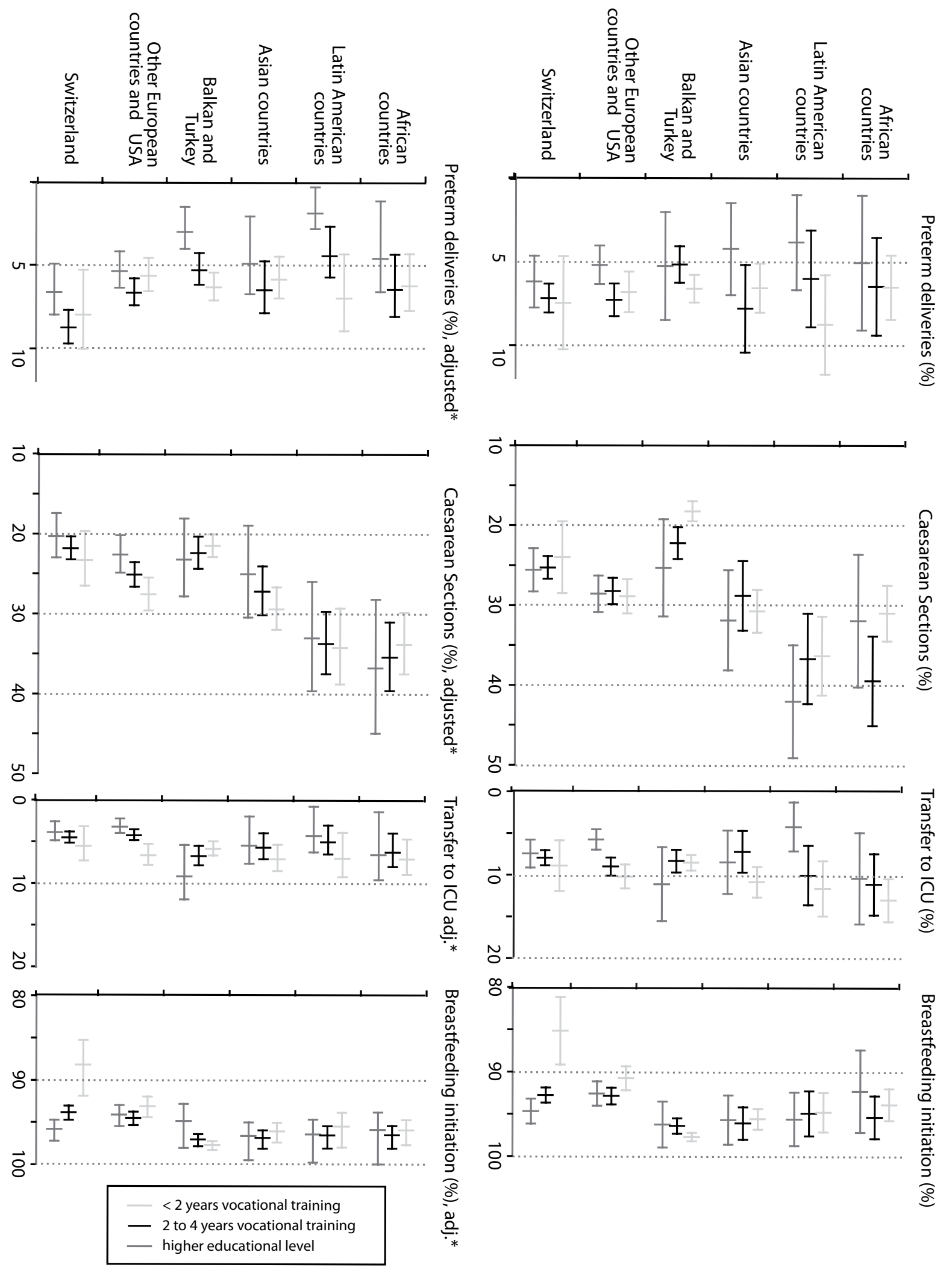

Figure 1 Crude and adjusted proportions of preterm deliveries (singletons), Cesarean sections, transfers to ICU and breastfeeding initiation and respective $95 \%$ confidence intervals, stratified by educational level 
$1 \%$ of the infants were weaned for medical reasons such as an HIV infection. Only in 3 national groups did medical indications exceed 2\%: $7 \%$ for Congolese mothers, $5 \%$ for Thai mothers, and $3 \%$ for Dutch mothers. This still only explains to a small extent, the high $\mathrm{C}$-section rate among Sub-Saharan African women.

Another reason for operative intervention during delivery is female genital circumcision. Thierfelder has estimated that $98 \%$ of Somalian women have undergone circumcision compared to only 5\% from the Democratic Republic of Congo (Thierfelder 2003). This still would not explain the high Csection rate of $38 \%$ among Congolese women, as compared to $28 \%$ among the Somalian women. Striking, though, is the high proportion of pre-term deliveries among Congolese women, who's babies also have the lowest average birth weight. Similar findings have been described for Sub-Saharan migrants in France (Zeitlin et al. 2004).

Another possible explanation of a high C-section rate may be the status quest. Migrants from resource-poor countries in Africa and Asia represent a higher- than- average social stratum in their country of origin. As such, they may be more likely to favour modern values, or to express their preference for a Caesarean section and actively seek medical technology as a means to control their birth (Liamputtong 2005; Donner 2003). In several Asian, African, and Latin American countries there has been a rise in the number of Caesarean sections in private hospitals, which far exceeds the national average (Belizan et al. 1999; Chanrachakul et al. 2000; Sreevidya \& Sathiyasekaran 2003; Ibekwe 2004). Maternal preference may partly contribute to the choice of a Caesarean section, but cannot explain the lower birth weight and higher number of preterm deliveries.

It should be noted that the interpretation of the differing Caesarean section rates in our study is limited, as we could not distinguish primary from secondary C-section. Another im- portant limitation on our analysis is the fact that we did not have systematically coded information about pregnancy complications, the nature of indications for Caesarean sections or for the transfers to the NICU. The data-set also provided no information about previous Caesarean sections, although these are important determinants for the mode of delivery, or on perinatal pathologies, and previous or current medication. For example, intrapartum analgesia would affect breastfeeding outcomes (Jordan et al. 2005; Merten et al. 2005a).

Also, the clinical records may contain inaccuracies. But the fact that the data-set is part of a continuous monitoring program, which is annually evaluated, strengthens the quality of the data.

\section{Conclusions}

In Switzerland, maternal education as a proxy for the socioeconomic level, and the country or region of origin, substantially influence the practices surrounding delivery. This implies that in the context of reproductive health care services, continuous attention needs to be paid to equity issues. Differences between mothers according to the combination of their socio-economic status and their origin should be taken into account.

\section{Acknowledgements}

In memoriam: Our friend and colleague Corinne Wyss deceased in 2006. We will remember her generosity and wonderful team spirit. She also contributed greatly to the establishment of the BFHI data-base in Switzerland.

We thank the Swiss Foundation for Breastfeeding Promotion for its support of the data-base, and the participating hospitals for their efforts regarding the data collection.

\section{References}

Aveyard P, Cheng KK, Manaseki S, Gardosi J (2002). The risk of preterm delivery in women from different ethnic groups. BJOG 109: 894-9.

Belizan JM, Althabe F, Barros FC, Alexander S (1999). Rates and implications of caesarean sections in Latin America: ecological study. BMJ 319: 1397-402.

Bewley S, Cockburn J (2002). The unfacts of 'request' caesarean section. Br J Obstet Gynaecol 109: 597-605.

BFS Bundesamt für Statistik (2005). Kaiserschnitt bei $29 \%$ aller Entbindungen in Schweizer Spitälern. Medienmitteilung Nr. 0350-0507-40.
Bollini P, Siem H (1995). No real progress towards equity: health of migrants and ethnic minorities on the eve of the year 2000. Soc Sci Med 41(6): 819-28.

Bollini P, Wanner $P$ (2006). Santé reproductive des collectivités migrantes. Disparités de risques et possibilities d'intervention. In: Forschung Migration und Gesundheit. Im Rahmen der Bundesstrategie "Migration und Gesundheit 2002-2007". Bern: Bundesamt für Gesundheit, 79-86.

Braveman $P$, Egerter $S$, Edmnonston $F$, Verdon $M$ (1995). Racial/Ethnic Differences in the Likelihood of Cesarean Delivery, California. Am J Public Health 85: 625-30. 
Gilgen D, Maeusezahl D, Salis Gross C, et al. (2005). Impact of migration on illness experience and help-seeking strategies of patients from Turkey and Bosnia in primary health care in Basel. Health \& Place 11: 261-73.

Griffiths LJ, Tate AR, Dezateux $C$ and the Millennium Cohort Study Child Health Group (2005). The contribution of parental and community ethnicity to breastfeeding practices: evidence from the Millennium Cohort Study. Int J Epid 2005: $1-9$.

Hall K (2004). The Ethnography of Imagined Communities: The Cultural Production of Sikh Ethnicity in Britain. Annals of the American Academy 595:108-21.

Hilfinger Messias DK (2002). Transnational Health Resources, Practices, and Perspectives: Brazilian Immigrant Women's Narratives. Journal of Immigrant Health 4(4): 183-200.

Horton S (2004). Different Subjects: The Health Care System's Participation in the Differential Construction of the Cultural Citizenship of Cuban Refugees and Mexican immigrants. Med Anthrop Q 18(4): 472-89.

Ibekwe PC (2004). Rising trends in caesarean section rates: an issue of major concern in Nigeria. Niger J Med 13(2): 180-1.

Ibison JM (2005). Ethnicity and mode of delivery in 'low-risk' first-time mothers, East London, 1988-1997. European Journal of Obstetrics \& Gynecology and Reproductive Biology 118: 199-205.

Jordan S, Emery S, Bradshaw C et al. (2005). The impact of intrapartum analgesia on infant feeding. BJOG 112: 927-34.

Lehmann P, Mamboury C, Minder C (1990). Health and Social Inequalities in Switzerland. Soc Sci Med 31: 369-86.

Leslie JC, Galvin SL, Diehl SJ, et al. (2003). Infant mortality, low birth weight, and prematurity among Hispanic, white, and African American in North Carolina. Am J Obstet Gynecol 188: 1238-40.
Liamputtong $P$ (2005). Birth and social class: Northern Thai women's lived experiences of caesarean and vaginal birth. Sociol Health Illn. 27(2): 243-7.

Matthias D, Pachaly J, Vetter K (2006). Perinatal outcome in Berlin (Germany) among immigrants from Turkey. Archives of Gynecology and Obstetrics. Archives of Gynecology and Obstetrics 274: 271-8.

McGlade MS, Saha S, Dahlstrom ME (2004). The Latina paradox: an opportunity for restructuring prenatal care delivery. Am J Public Health 94: 2062-5.

Merten S, Ackermann-Liebrich U (2004). Exclusive Breastfeeding Rates and Associated Factors in Swiss Baby-Friendly Hospitals. J Hum Lact 20(1): 9-18.

Merten S, Dratva J, Ackermann-Liebrich U (2005a). Do baby-friendly hospitals influence breastfeeding duration on a national level? Pediatrics 116(5): e702-8.

Merten S, Dratva J, Ackermann-Liebrich $U$ (2005b). Säuglingsernährung in den ersten 9 Lebensmonaten - nationale Studie 2003. In: Eichholzer M, Camenzind-Frey E, Matzke A, et al. Fünfter Schweizerischer Ernährungsbericht. Bern: Bundesamt für Gesundheit, 109-23.

Page RL (2004). Positive pregnancy outcomes in Mexican immigrants: what can we learn? J Obstet Gynecol Neonatal Nurs 33: 783-90.

Philipp BL, Merewood A, Miller LW, et al. (2001) Baby-Friendly Hospital Initiative improves breastfeeding initiation rates in a US hospital setting. Pediatrics 108(3): 677-81.

Portes A, Rumbaut RG (2001). Legacies: The story of the immigrant second generation. Berkeley: University of California Press.

Rizzo N, Ciardelli V, Gandolfi Colleoni G et al. (2004). Delivery and Immigration: The Experience of an Italian Hospital. European Journal of Obstetrics \& Gynecology and Reproductive Biology 116(2): 170-2.
Ruowei L, Grummer-Strawn L (2002). Racial and Ethnic Disparities in Breastfeeding among United States Infants: Third National Health and Nutrition Examination Survey 1988-1994. Birth 29(4): 251-7.

Sreevidya S, Sathiyasekaran BWC (2003). High caesarean rates in Madras (India): a populationbased cross sectional study. BJOG 110: 106-11.

Thierfelder $C$ (2003). Female Genital Mutilation And the Swiss Health Care System. Dissertation University of Basel, Switzerland.

Wanner P, Bouchardy C, Raymond L (2000). Mortalité des étrangers en Suisse. Analyse par grand groupe des causes et par type de cancer 19891992. Office federal de la Statistique. Neuchâtel.

World Health Organisation Euro (2003). Sexual and Reprodutctive health in a Multicultural Europe. Entre Nous. The Magazine for Sexual and Reproductive Health 55: 10.

World Health Organisation (1991). Indicators for Assessing Breast-feeding Practices. Geneva: World Health Organisation Publication WHO/ CDD/SER/91.14.

Zeitlin J, Bucourt B, Rivera L, et al. (2004). Preterm birth and maternal country of birth in a French district with a multiethnic population. BJOG 111: 849-55.

Address for correspondence

Sonja Merten, MD MPH

Institute of Social and

Preventive Medicine

University of Basel

Steinengraben 49

CH-4051 Basel

e-mail: sonja.merten@unibas.ch
To access this journal online: http://www.birkhauser.ch/IJPH 